\title{
ANALISIS PENGEMBANGAN APLIKASI TRILINGUAL BAHASA INDONESIA, GORONTALO DAN SUWAWA BERBASIS ANDORID
}

\author{
Frangky Tupamahu ${ }^{1}$, Andi Mariani ${ }^{2}$ \\ Program Studi Teknik Informatika, Politeknik Gorontalo ${ }^{(1}$ \\ Program Studi Matematika UIN Alauddin ${ }^{2}$ \\ Email: frangkytupamahu@poligon.ac.id ${ }^{1}$ \\ Indonesia
}

\begin{abstract}
ABSTRAK
Sistem aplikasi bilingual mulai dari versi pertama hingga yang terbaru (Ibrahim 2015), maka perlu dilakukan pengukuran dan analisis lebih lanjut. Salah satu analisis yang penting dilakukan adalah analisis tingkat efektivitas dari aplikasi yang dikembangkan. Oleh karena itu, dalam penelitian ini dilakukan analisis tingkat efektivitas yang bertujuan untuk mengetahui kualitas aplikasi "Bilingual Indonesia, Gorontalo, Suwawa" yang dikembangkan oleh (Ibrahim 2015), dari hasil penelitian tersebut diperoleh kesimpulan bahwa pengembangan perangkat lunak aplikasi "Trilingual Bahasa Indonesia, Gorontalo dan Suwawa", menggunakan 4 aspek alat uji diperoleh hasil bahwa : 1) efisiensi kemampuan aplikasi 2,236 detik dengan predikat "sangat puas"; 2) aplikasi setelah diinstal pada perangkat android 4.0 ke atas secara fungsi sebesar $100 \%$, sesuai dengan standar kualitas dari AquA dapat berjalan dengan baik; 3) portabel dari sisi admin dan pengguna,hasil sebesar $100 \%$ dengan predikat "sangat tinggi"; 4) aspek kegunaan dari 20 orang responden yang telah menginstal aplikasi di perangkat android mereka diperoleh hasil sebesar 1607 dengan predikat "sangat layak". Hasil pengujian aplikasi "Trilingual Bahasa Indonesia, Gorontalo dan Suwawa" dapat dikatakan memberikan hasil bahwa aplikasi ini telah memiliki kemampuan secara efisien, serta stabil dan dapat di pasang pada minimal versi android 4.0 Ice Cream Sandwitch, dan mudah digunakan oleh pengguna yang belum mengetahui cara penggunaannya.
\end{abstract}

\section{Kata kunci: Android, Kamus, Tiga Bahasa, Efisiensi Performa}

\section{ABSTRACT}

The bilingual application system starts from the first version to the newest one (Ibrahim 2015); it is necessary to carry out further measurements and analysis. One of the essential analyzes to do is to analyze the effectiveness of the application be developed. Therefore, in this study, an analysis of the level of significance was carried out to determine the quality of the application "Bilingual Indonesia, Gorontalo, Suwawa" developed by (Ibrahim 2015). From the results of this study, it concluded that the application software development "Trilingual Indonesian Language, Gorontalo. and Suwawa", using four aspects of the test equipment, the results showed that (1) The efficiency of the application ability was 2.236 seconds, with the predicate very satisfied, (2) After being installed on an Android 4.0 device and above is $100 \%$ functional, the application will run properly by the quality standards of AquA, (3) Portable from the admin and user perspective, the result is $100 \%$ with the predicate "extremely high.", (4) The usability aspect of the 20 respondents who have installed the application on their Android device results in 1607 with the predicate "very feasible". The test results of the application "Trilingual Indonesian, Gorontalo and Suwawa" can be said to provide results that this application is efficient, stable and can be installed on at least the Android version 4.0 Ice Cream Sandwich, and easy to use by users who do not know how to use it.

Keywords: Android, Dictionary, Three Languages, Performance Efficiency

\section{PENDAHULUAN}

Bahasa merupakan salah satu media komunikasi yang sangat penting bagi manusia, bahasa juga terdiri dari bermacam-macam bahasa. Setiap daerah mempunyai bahasa yang berbeda-beda yang digunakan sebagai media komunikasi. Adapun permasalahan yang muncul yaitu penggunaan bahasa daerah saat ini sudah mulai ditinggalkan dalam berkomunikasi sehari-hari, hal ini terlihat dari sebagian besar generasi muda yang lebih suka menggunakan bahasa gaul atau bahasa anak muda zaman sekarang dibandingkan dengan bahasa daerah mereka sendiri.

Untuk dapat mengatasi masalah tersebut maka telah dibuat aplikasi bilingual berbasis android, karena saat ini handphone berbasis Android banyak digunakan di kalangan anak muda jaman sekarang. Versi pertama dibuat oleh Mances Malingo 2012, namun pada aplikasi tersebut masih terdapat kekurangan diantaranya pada aplikasi tersebut tidak menyediakan fasilitas kontributor untuk menambahkan database bahasa daerah yang baru. Selanjutnya Hais Pomanto 2013, mengembangkan 
apikasi bilingual versi kedua dengan menambahkan fitur - fitur yang belum ada sebelumnya yakni bersifat client server dimana data bahasa client akan sering diupdate selain itu ditambahkan fasilitas kontributor. Dengan melihat dan me-review aplikasi versi pertama dan kedua, (Ibrahim 2015) masih menemukan ada beberapa fitur yang belum ditambahkan diantaramya bahasa daerah Suwawa, dan jumlah database setiap daerah masih sedikit dan belum di online-kan sehingga merancang aplikasi bilingual dalam bentuk online sistem dan diintegrasikan dengan bahasa Suwawa dan lebih interaktif.

Dengan adanya berbagai aplikasi bilingual mulai dari versi pertama hingga yang terbaru (Ibrahim 2015), maka perlu dilakukan pengukuran dan analisis lebih lanjut. Salah satu analisis yang penting dilakukan adalah analisis tingkat efektivitas dari aplikasi yang dikembangkan. Berdasarkan hal tersebut sebagaiman telah dijabarkan pada paragraft sebelumnya, penelitian akan melakukan analisis tingkat efektivitas yang bertujuan untuk mengetahui kualitas aplikasi "Bilingual Indonesia, Gorontalo, Suwawa" yang dikembangkan oleh (Ibrahim 2015) denang mempertimbangkan beberapa aspek pengukuran untuk mengukur kinerja aplikasi tersebut berdasarkan aspek efisiensi terhadapt performa aplikasi, penggunaan fungsi pada interaksi oleh pengguna. Aspek selanjutnya, pengujian terhadap kemampuan aplikasi saat di pasang pada platform android berbagai macam seri sistem operasi dan menjadi aspek terakhir adalah pengujian terhadap kepuasan pengguna setelah mereka mencoba aplikasi yang telah di bangun.

\section{METODE PENELITIAN}

Dalam proses penelitian yang dilakukan, penelitia mengikuti prosedur standar ISO 25010 sebagai prosedur untuk melakukan pengujian yang terdiri atas 8 aspek kualitas dalam standar tersebut. Akan tetapi oleh peneliti dalam penelitian ini hanya mengguanakan hanya mengambil 4 faktor sebagai fokus pengujian yang paling relevan dengan penelitian yang dilakukan. Ke empat faktor tersebut yaitu efisiensi kinerja, kesesuaian fungsi, portabilitas, dan kegunaan.

\subsection{Kerangka Berfikir}

Penelitian tentang analisis pengembangan aplikasi "Tringual Bahasa Indonesia, Gorontalo dan suwawa" berbasis android berfokus Keempat faktor tersebut yaitu efisiensi kinerja, kesesuaian fungsional, portabilitas, dan kegunaan. Penulis memilih keempat aspek kualitas tersebut karena aspek-aspek tersebut yang paling relevan dengan penelitian yang dilaksanakan. Aspek tersebut juga merupakan pengujian yang perlu dilakukan untuk menguji suatu perangkat lunak pada aplikasi yang dikembangkan untuk versi mobile. Dalam Penelitian ini diawali dengan ditemukannya permasalahan penelitian yang memunculkan alternatif penyelesaian masalah.

\subsection{Desain Penelitian}

Objek penelitian dalam penelitian ini adalah pengembangan perangkat lunak aplikasi "Trilingual Bahasa Indonesia, Gorontalo dan Suwawa" berbasis android.

Pengujian ini dilakukan secara operasional oleh penulis dengan metode observasi. Pada tahap ini dilakukan pengujian terhadap aspek kualitas efisiensi kinerja, kesesuain fungsi dan kegunaan. Beta testing dilakukan dengan menggunakan metode kuesioner kepada sejumlah responden. Responden diambil dengan menggunakan teknik purposive sampling dengan jumlah responden sebanyak 20 (responden uji beta). Pengujian beta sendiri dimaksudkan untuk mengetahui kelayakan program dilihat dari aspek kualitas usability.

Desain pengujian masing-masing aspek kualitas dilakukan dengan menggunakan metode yang berbeda. Analisis terhadap data yang didapatkan juga dilakukan dengan cara yang berbeda pula. Desain penelitian untuk masing- masing aspek kualitas adalah sebagai berikut, pertama pengukuran terhadap Aspek efisensi performa aplikasi dengan cara menghitung respon aplikasi dengan server sebanyak 3-5 kali dan hasil repons tersebut di hitung kemudian dibandingkan dengan tabel pemetaan kepuasan pengguna. Aspek yang kedua pengukuran berdasarkan aspek kualitas kestabilan fungsi yang dalam proses dilakukan menggunakan pengujian kasus yang di isi oleh seorang pakar sebanyak 3 orang kemudian hasilnya di bandingkan dengan standar fungsi pengukuran AQUA. Aspek yang ketiga aspek kemampuan aplikasi yang dapat beradaptasi dengan sistem operasi, diteliti dengan melakukan pengujian pada berbagai versi sistem operasi android (Ice Cream sampai dengan kitkat) dan menggunakan compatibility testing yang ada di Google Play Store. Kemudian dilakukan analisis deskriptif untuk menghasilkan kesimpulan. Aspek keempat, kemampuan suatu aplikasi untuk dipahami yang disebut dengan Faktor kualitas usability yakni ketercapaian pengguna dalam menguasai aplkasi yang telah di buat. Dalam penelitian ini dilakukan analisa dengan menggunakan sistem komputerasi pada 20 orang yang menjadi responden dalam hal ini menggunakan teknik yang telah dikembangkan sebelumnya oleh JR Lewis. 


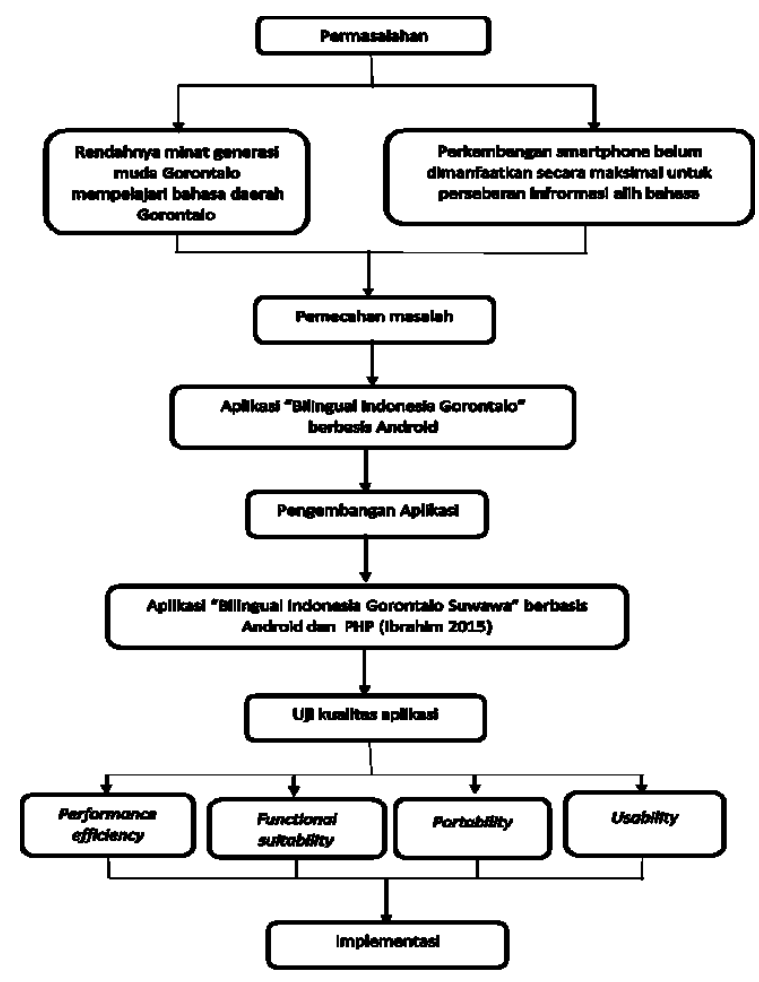

Gambar 1. Desain Penelitian Analisis Pengembangan Aplikasi Trilingual Bahasa Indonesia, Gorontalo dan Suwawa Berbasis Andorid.

\subsection{Objek Penelitian}

Objek dalam penelitian mengikuti mengacu pada kriteria penelitian untuk menguji dan atau analisis untuk perangkat lunak sebagai mana yang telah di uraikan secara jelas mengikuti teori standar ISO 25010.

\subsubsection{Efisiensi Kemampuan Perangkat Lunak}

Efisiensi kemampuan perangkat lunak adalah pengukuran untuk mengukur kinerja suatu aplikasi yang dapat digunakan segala kondisi dalam arti handal sehingga aspek pengukuran ini penting mengingat bahwa aplikasi tersebut di pasang pada sistem ponsel cerdas.

\subsubsection{Kemampuan Adapatasi Fungsi Aplikasi}

Karakteristik ini merepresentasikan sejauh mana produk atau sistem menyediakan fungsi yang memenuhi kebutuhan yang dinyatakan dan tersirat ketika digunakan dalam kondisi tertentu.

\subsubsection{Portable sistem}

Pengukuran terhadap kemampuan sistem aplikasi yang di telah dibuat apakah mampu untuk dijalan di berbagai bentuk platform sistem operasi pada perangkat ponsel cerdas.

\subsubsection{Usability}

Usability merupakan faktor kualitas yang mengukur usaha yang dibutuhkan untuk mempelajari, mengoperasikan, memberikan input, dan menginterpretasikan output dari suatu program (Pressman, 2002: 612).

\subsection{Teknik Akuisisi data}

Teknik pengakuisisian data dalam penelitian ini dilakukan dengan cara obeservasi dan pengumpulan angket kuisioner.

\subsubsection{Observasi}

Observasi dilakukan dengan melakuk anpengamatan langsung terhadap objek pe nelitiandibantu dengan beberapa instrumen khusus sebagai alat bantu pengukuran $\mathrm{Me}$ tode observasi dilakukan untuk mengetahui kelayakan program dari segi efisiensi, fungsionalitas, dan Portabel.

\subsubsection{Kuisioner}

Kuisioner digunakan untuk mengetahui kelayakan perangkat lunak aplikasi Trilingual Bahasa Indonesia, Bahasa Gorontalo dan Bahasa Suwawa dari segi usability. Kuisioner akan diujikan kepada responden sebanyak 20 orang (responden uji beta). Pemilihan responden dilakukan dengan metode purposive sampling.

\subsection{Alat Ukur Penelitian}

Alat ukur penelitian menurut (Sugiyono, 2010:148) merupakan suatu alat untuk dipakai agar mendapatkan suatu nilai dari perubahan alam yang terjadi juga perubahan social sehingga mampu melakukan kuantifikasi terhadap suatu objek yang diteliti.

Pengertian sejenis juga telah di tuliskan dalam buku mengurai variable hingga menjadi Instrumen yang dikarang oleh (Mustafa 2009:50, dalam bukunya menyebutkan bahwa: "Apabila instrumen untuk suatu konsep belum tersedia, maka peneliti bisa membangun instrumen (alat ukur) baru, tetapi jika pernah atau telah ada, maka peneliti dapat mengembangkan (melakukan penyesuaian seperlunya) terhadap instrumen yang telah ada tersebut, dapat pula langsung menggunakan begitu saja apa adanya instrumen tersebut (instrumen tersebut harus relevan dan telah teruji).

Dengan mengacu pada pernyataan para pakar yaitu sugiyo dan Mustafa, pada penelitian analaisis pengembangan aplikasi trilingual, kami sebagai peneliti menggunakan beberapa variable yang berbeda untuk dijadikan instrument untuk mengukur analisis pengembangan aplkasi trilingual bahasa Indonesia, Gorontalo dan Suwawa berbasis andorid. Alat ukur yang menjadi instrumen penelitian dikembangkan oleh penulis sendiri, adalah suatu alat ukur yang valid dan dijadikan instrumen yang telah banyak digunakan sebelumnya.

\subsubsection{Alat Ukur Efisiensi}

Dalam alat ukur efisiensi, dilakukan pengujian pada perangkat lunak yang dikembangan menggunakan interpreter Eclipse dan ADT (Android Development Tool) dan telah dipasangkan pada ponsel cerdas Samsung koneksi $4 \mathrm{G}$ sistem operasi android 4.1 Ice Cream . untuk konektivitasnnya menggunakan provider Telkomsel dan IM3 


\subsubsection{Alat ukur Fungsionalitas}

Pengujian ini dilakukan dengan menggunakan test case. Dalam bukunya yang berjudul Software Engineering and Testing, agarwal dkk (2010:179) menjelaskan pengertian test case sebagai berikut: "Sebuah testcase adalah sekumpulan instruksi yang dirancang untuk menemukan suatu kesalahan atau cacat dalam sistem perangkat lunak demi mengurangi kegagalan."

Penggunaan uji kasus (testcase) memiliki tujuan agar memastikan validasi kesalahan pada program tersebut sedikit. Sehingga jika dalam proses pengujian di dapati kesalahan ataupun error, dapat di deteksi dan kemudian dilakukan perbaikan dari error tersebut. Harapan besar dilakukan dengan cara melakukan test case dapa dilaksanakan secara ideal dalam arti cakupan pengujian program dilakukan scara menyeluruh dan terdokuementasi secara baik.

Adapun format pengujian yang digunakan oleh pada penelitian ini ditunjukan pada tabel 1 berikut.

Tabel 1. Indikator uji kasus yang digunakan

\begin{tabular}{|c|c|}
\hline Atribut & Keterangan \\
\hline Prosedur & $\begin{array}{l}\text { Ururan skenario berdasrkan } \\
\text { prosedur }\end{array}$ \\
\hline Opsi pilihan & $\begin{array}{l}\text { Aktivitas yang dilakukan } \\
\text { Pengguna dengan aplikasi }\end{array}$ \\
\hline Kesesuaian hasil & $\begin{array}{l}\text { Hasil yang diperoleh berdasarkan } \\
\text { Interaksi pengguna dengan } \\
\text { aplikasi }\end{array}$ \\
\hline Nilai capaian & $\begin{array}{l}\text { Nilai ketercapaian } \\
\text { pengujian (ya/tidak) }\end{array}$ \\
\hline
\end{tabular}

\subsubsection{Alat Ukur Efektivitas dan Efisiensi}

Dalam penelitian ini penggunan alat uji portability bertujuan untuk mengetahu sejauh mana kemampuan aplikasi yang telah di buat dapat dipasang dan dioperasikan pada berbagai macam platform ponsel cerdas dengan sistem operasi yang berbeda pula mulai dari versi android 4.0x Ice Cream Sandwitch hingga ke versi terkini yaitu android 10 yang dilengkapi dengan fitur tema dapat berubah baik tema gelap maupun terang. Pengukuran menggunakan versi android 10 penting untuk dilakukan hal ini dikarenakan perangkat cerdas berbasis android telah sempurna dan telah banyak di gunakan oleh semua industri yang memproduksi perangkat cerdas dengan sistem operasi android.

Untuk dapat secara maksimal memperoleh hasil yang baik menggunakan alat ukur efektivitas dan efisiensi, dalam penelitian ini penulis menggunakan instrument (SUS) yang di kembangkan oleh Jhon Brooke untuk mengukur kualitas suatu aplikasi yang berdasarkan hasil penilaian kuisioner yang di isi oleh responden. Adapun isi atribut ukur yang menjadi opsi pilihan oleh responden dimulai dari kepuasan yang terukur yaitu kualitas sangat setuju, setuju, netral, tidak setuju dan terakhir adalah sangat tidak setuju.

\subsection{Teknik Analisa Data}

\subsubsection{Analisis Faktor}

\section{Kemampuan Aplikasi}

Dalam proses analisa data untuk mendapatkan nilai kualitas yang efisien dari kemampuan aplikasi trilingual yang telah di kembangkan, dilakukan menggunakan indikator waktu respons oleh sistem saat pengguna melakukan akses informasi dalam aplikasi yang tersingkron dengan basis data tempat penyimpanan informasi. Pengukuran terhadap aspek kualitas aspek efektifitas kemampuan aplikasi yang di rancang, dilakukan perhitungan rata - rata waktu yang diperoleh aplikasi untuk mengakses sumber data pada data base dari hasil instruksi oleh pengguna saat melakukan uji coba pada aplikasi yang dibuat. Dalam proses interaksi ini pengguna memasukan kata yang di cari yang telah tersedia dalam basis data selanjutnya oleh sistem menampilkan hasil pencarian tersebut untuk di tampilkan. Selanjutnya pengguna memberikan masukan dan nilai. Adapun proses tersebut ditunjukan pada gambar 2 berikut ini.

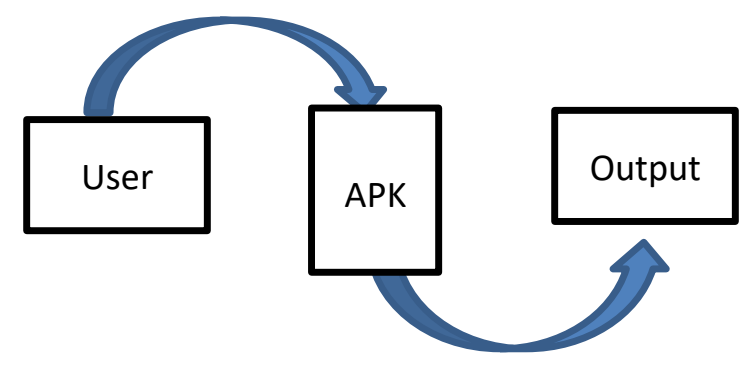

Gambar 2. Prosedur Analisis Faktor Kualitas efisiensi kemampuan aplikasi

Adapun pengukuran waktu rata-rata mengacu pada table 2 dengan perolehan hasil yang terbaik dibawah 3 detik begitupun dengan hasil yang kurang baik dipilih oleh pengguna berdasarkan waktu lebih dari 12 detik.

Tabel 2. Pemetaan Pengukuran Kepuasan Pengguna

\begin{tabular}{cc}
\hline Respon waktu (detik) & Rating \\
\hline$<3$ & Sangat puas \\
$3-9$ & Puas \\
$9-12$ & Cukup puas \\
$>12$ & Tidak Puas \\
\hline
\end{tabular}

\subsubsection{Analisis Faktor Kualitas Fungsi aplikasi}

Aplikasi yang telah dilakukan pengujian mengunakan faktor kualitas efisiensi dari suatu aplikasi dan diperoleh data serta rekaman kusioner, kami peneliti melanjutkan perbadingan dari hasil tersebut dengan parameter ukur yang telah di standarkan oleh App Quality Alliance (AQuA). Dengan mengacu pada kriteria standar Aqua kami 
peneliti melakukan analisis dari hasil yang di peroleh pada saat melakukan pengujian efisiensi aplikasi yang telah di bangun. Apa bila masuk dalam standar tersebut makanya aplikasi yang telah di buat memunhi dan dianggap sebagai aplikasi dengan kualitas baik.

Kriteria ukur AQua yang digunakan untuk menjadi parameter adalah pengukuran fungsi aplikasi saat digunakan oleh pengguna. Sehingga dalam melaukan pengukuran ini diperoleh suatu kesimpukan bahwa aplikasi Trilingual Bahasa Indonesia, Gorontalo dan Suwawa berbasis andorid ini secara fungsi baik algortima,akses data informasi dalam basis data dan lain sebagainya berjalan sesuai dengan ketentuan dan kriteria yang telah di atur dalam standaar kriteria Aqua dan dapat dikatakan memenuhi standar fungsi atau tidak.

\subsubsection{Analisis Faktor Kualitas fungsionalitas Aplikasi}

Dalam pengujian secara fungsi pada aplikasi "Trilingual Bahasa Indonesia, Bahasa Gorontalo dan Bahasa Suwawa". Dilakukan pengujian dengan memasang aplikasi tersebut pada berbagai versi android seperti ditunjukan pada tabel 3 berikut.

Tabel 3 Versi Android

\begin{tabular}{cl}
\multicolumn{2}{c}{ Tabel 3 Versi Android } \\
\hline Versi & \multicolumn{1}{c}{ Nama } \\
\hline $4.0 .3-4.0 .4$ & Ice Cream Sandwitch \\
$4.1 . \mathrm{x}$ & Jelly Bean \\
$4.2 . \mathrm{x}$ & Jelly Bean \\
4.3 & Jelly Bean \\
$4.4-4.4 .4$ & Kitkat \\
$5.0-5.11$ & Lolipop \\
$6.0-6.0 .1$ & Mashmellow \\
$7.0-7.1 .2$ & Nougat \\
8.0 & Oreo \\
9.0 & Pie \\
\hline
\end{tabular}

Adapun Perhitungan dilakukan dengan rumus 1 sebagai berikut:

\section{Presentase Portability $=$}

skor yang didapatkan skor maksimal

\subsubsection{Analisis Faktor Kualitas Aspek Usability}

Pengujian berikut yang dilakukan pada penelitian ini adalah melakukan analisa berdasarkan faktor kualitas aspek usability pada aplikasi "Trilingual Bahasa Indonesia, Bahasa Gorontalo dan Bahasa Suwawa". Dalam pengukuran ini, dilakukan dengan membagikan angket bentuk kisioner kepada responden minmal 30 orang. 30 orang tersebut pertama-tama melakukan ujicoba aplikasi yang telah di buat. Mulai dari proses instalasi sampai dengan proses akses setiap fitur-fitur yang ada dalam aplikasi tersebut. Dalam proses pengujian tersebut, semua responden diminta untuk mengamati aplikasi selama digunakan dengan batasan waktu kurang lebih 5-6 menit. Sembari mengkases apliaksi tersebut semua responden di berikan angket kuisioner untuk menjawab 19 pertanyaan yang ada pada angket tersebut dan memeberikan respons mengikuti atribut yang telah di konfersi kedalam angka. Adapun atribut tersebut di sajikan pada tabel 4 berikut.

Tabel 4. Konversi Jawaban Kuisioner

\begin{tabular}{cc}
\hline Atribut Kuisioner & NIlai konversi \\
\hline Sangat Setuju (SS) & 5 \\
Setuju (S) & 4 \\
Netral (N) & 3 \\
Tidak Setuju (TS) & 2 \\
Sangat Tidak Setuju & 1 \\
\hline
\end{tabular}

Setelah didapatkan hasil dari kuisioner yang dibagikan kepada 30 orang responden yang telah diketahui merupakan dari kualitatif, hasil-hasil tersebut dikonfersi menjadi data keuantitiatif yang memiliki nilai terendah 1 dan tertinggi 5. Semakin tinggi nilai yang diperoleh menunjukan aplikasi tersebut baik secara kualitas fungsi kegunaaan. Datadata yang telah diperoleh tersebut kemudian dilakukan pengecekan serta memastikan apakah pada setiap pertanyaan yang di sajikan telah di isi tanpe memperdulikan hasil isian karena telah di ketahui bahwa dari 30 respondesn yang digunakan memiliki tingkat pemahaman dan cara berfikir yang berebeda untuk menilai aplikasi yang ingin diujikan. Setelah diperoleh angket dan memastikan bahwa seluruh angket telah di isi, penulis melakukan pengolahan data-data tersebut dengan dibantu perangkat lunak WEKA untuk mendaptkan nilai hasil nilai statistik dari setiap butir pertanyaan pada angket. Nilai-nilai tersebut kemudian dilakukan pengelompokan berdasarkan kategori kelayakan sebagaimana di tunjukan pada tabel 4. Secara lengkap pengelompokan nilai tersebut diperoleh menggunakan 3 perhitung yaitu jumlah kategori, jangkauan nilai data, panjang kelas kategori.

Jumlah kategori dalam pengkategorian ini digunakan sebanyak 5 jenis kategori yang mendukung data angket bentuk kuisioner sebanyak 19 pertanyaan yang di bagikan kepada 30 orang responden untuk diisi.

Jangkauan nilai data untuk mendapatkan hasil pengukuran adalah dengan melakukan perhitungan selisih antara jumlah nilai maksimum dengan jumlah nilai minimum. Menggunakan rumus 2 dan 3 berikut

$$
\begin{aligned}
& \mathrm{X}=\text { Jml skor mak } \\
& \mathrm{Y}=\text { Jml Skor Min } \\
& \mathrm{A}=\text { Skor Mix } \\
& \mathrm{B}=\text { Skor Max } \\
& \mathrm{C}=\text { Jumlah Soal } \\
& \mathrm{D}=\text { Jmlh Responden }
\end{aligned}
$$


Maka $\mathrm{X}=\mathrm{A} \times \mathrm{C}$ x D

Maka $\mathrm{Y}=\mathrm{B} \times \mathrm{C} \times \mathrm{D}$

Kemudian untuk jangkaun nilai data diperoleh berdasarkan rumus 4 berikut :

Jangkauan Nilai data $=\mathrm{X}-\mathrm{Y}$

Panjang kelas kategori setelah di peroleh jangkaun nilai data, dilakukan perhitungan untuk medapatkan nilai panjang kelas kategori, dengan membagi jangkauan nilai data dengan jumlah kelas yang digunakan sebanyak 5 kelas. menggunakan rumus 5 berikut.

$$
\begin{aligned}
& \mathrm{Z}=\text { Panjang Kategori Kelas } \\
& \mathrm{P}=\text { Panjang Kelas Kategori } \\
& \mathrm{JK}=\text { Jumlah Kelas } \\
& \text { JND = Jangkauan Nilai Data }
\end{aligned}
$$

$\mathrm{Z}=\mathrm{JND} / \mathrm{JK}$

adapun perhitungannya adalah sebagia berikut :

$$
\begin{aligned}
\mathrm{P} & =\mathrm{JND} / \mathrm{JK} \\
& =1520 / 5 \\
& =304
\end{aligned}
$$

Tahapan pengkategorian ini menggunakan pendekatan yang umum digunakan akan tetapi memiliki batasan kelas yang memiliki interval nilai dari 380 - 1900 untuk dapat digunakan menguji tingkat kelayakan pada aspek kegunaan. Kategori tingkatan kelayakan asepk kulitas kegunaan ditunjukan pada tabel 5 berikut.

Tabel 5. Kategorisasi Tingkat Kelayakan Aspek Kualitas

\begin{tabular}{cc}
\multicolumn{2}{c}{ Kegunaan. } \\
\hline Kategori & Skor \\
\hline Sangat Tidak Layak & $380-684$ \\
Tidak Layak & $684-988$ \\
Cukup Layak & $988-1292$ \\
Layak & $1292-1596$ \\
Sangat Layak & $1596-1900$ \\
\hline
\end{tabular}

\section{HASIL DAN PEMBAHASAN}

Dalam melakukan analisis pengembangan aplikasi trilingual bahasa Indonesia, Gorontalo dan Suwawa Berbasis Andorid, menggunakan prosedur tahapan penleitian sebagai telah di uraikan pada sub bab sub bab sebelumnya dengan harapan diperoleh hasil yang baik dan mampu untuk melakukan identifikasi sehingga terdekteksi kesalahan baik dari sisi algoritma dan ketidaksempurnaan dari program yang telah di buat. Sehingga jika dapati, dalam dilakukan perbaikan-perbaikan baik dari algoritma dan deskripsi program agar diperoleh hasil yang lebih baik. Dalam penelitian ini penulis melakukan 2 tahapan umum digunakan yaitu pengujian secara alpa dan pengujian secara beta. Pengujian alpa, penulis melakukan pengukuran menggunakan pendekatan empat aspek sebagaiman di sajikan pada tabel 6 berikut.
Tabel 6. Pengujian Alpa dan Beta.

\begin{tabular}{cc}
\multicolumn{2}{c}{ Aspek } \\
\hline \multicolumn{2}{c}{ Tabel 6. Pengujian Alpa dan Beta. } \\
\hline Pengujian Alpa & Pengujian Beta \\
Correctness & Faktor kualitas \\
functional siutability & aspekusability \\
portability & \\
\hline
\end{tabular}

Pengujian pertama dilakukan dengan Perangkat uji : Smartphone Samsung J One dengan Sistem Operasi : Android Ice Cream Sandwitch (4.0) Konektivitas : HSDPA (provider Telkomsel) Lokasi Uji : SMK N 1 Motilango.

Setelah dilakukan pengujian terhadap efisensi performaa kualitas aplikasi trilingual, dilanjutkan pengukuran untuk menghitung rerata waktuyang dibutuhkan untuk aplikasi merespon informasi yang diberikan oleh pengguna dan waktu respons aplikasi saat melakukan akses basis data kata yang digunakna untuk konversi Bahasa Indonesia, Gorontalo dan Suwawa. Pengujian terhadap efisensi performa diperoleh dari hasil pengujian yang dilakukan sebanyak 5 kali dengan 13 aktivitas yang telah diformat untuk lakukan saat mengakses konten dalam aplikasi tersebut. Dari 5 kali pengujian, diperoleh hasil jumlah skor 36,000. Adapun cara menghitung waktu rerata tersebut sebagai berikut:

$$
\begin{aligned}
& \text { waktu rata }- \text { rata }=\frac{\sum \text { Skor yang diperoleh }}{5 \times \text { aktivitas }} \\
& \text { waktu rata }- \text { rata }=\frac{86.000}{5 \times 13} \text {. }
\end{aligned}
$$

Dari hasil pengujian tersebut di peroleh waktu rerata yng dibuthkan untuk melakukan akses adalah 2,236 detik. maka nilai angka tersebut mendapatkan predikat "Sangat Puas". Dengan demikian maka dapat disimpulkan bahwa aplikasi "Trilingual Bahasa Indonesia,Bahasa Gorontalo dan Bahasa Suwawa" telah memenuhi aspek kualitas performance efficiency.

Langkah selanjutnya adalah melakukan pengukuran aspek kulaitasi kegunaan aplikasi yang telah dibuat. Dalam proses ini aplikasi di install pada 20 orang yang memiliki perangkat android dengan jenis android yang beragam tanpa memperhatikan merek android yang digunakan. Selanjutnya, para responded yang telah menginstal aplikasi trilingual Bahasa Indonesia, Gorontalo dan Suwawa di ponsel cerdas responded, kemudian para responden melakukan aktivitas pada palikasi itu diminta untuk mengisi kuisioner yang didalmnya terdapat 19 butir soal untuk diisi oleh responden berdasarkan pengalaman saat mengakses aplikasi yang telah dibuat. Adapun perolehan hasil Pengujian aspek kualitas kegunaan dapat dilihat pada gambar berikut ini. 


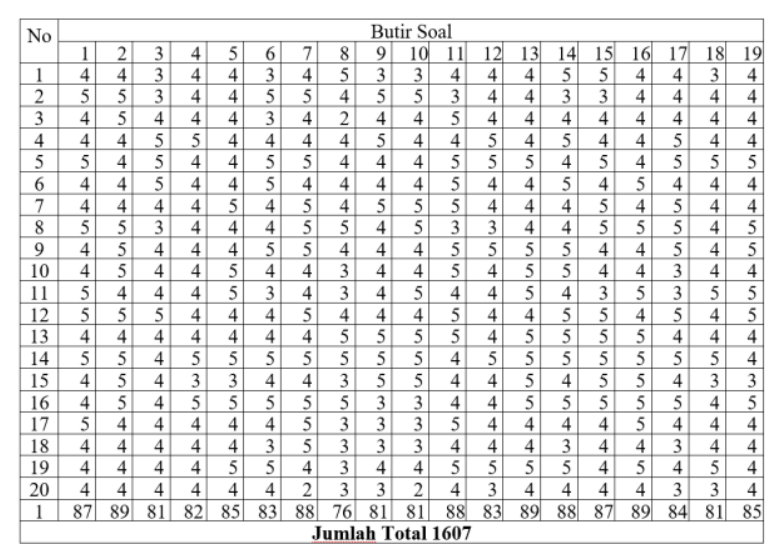

Gambar 3. Hasil Pengujian Aspek Kualitas Usability

Berdasarkan hasil pengumpulan dan analisis data dari jumlah 20 responded, diperoleh hasil jumlah total nilai yang diperoleh adalah 1607. Total nilai tersebut, selanjutnya dikonversi mengikuti tabel 4 diperoleh bahwa aplikasi "Trilingual Bahasa Indonesia, Gorontalo dan Suwawa" telah memenuhi aspek kualitas usability dengan nilai jika dikonversi masuk dalam kategorisasi tingkat kelayakan aspek kualitas kegunaan dengan status kategori "sangat layak"

\section{KESIMPULAN DAN SARAN}

Dari hasil penelitian yang dilakukan diperoleh kesimpulan bahwa pengembangan perangkat lunak aplikasi "Trilingual Bahasa Indonesia, Gorontalo dan Suwawa", menggunakan 4 aspek alat uji diperoleh hasil bahwa : 1) performance efficiency sebesar 2,236 detik dengan predikat "sangat puas"; 2) aplikasi setelah diinstal pada perangkat android 4.0 ke atas secara fungsi sebesar $100 \%$, sesuai dengan standar kualitas dari AquA dapat berjalan dengan baik; 3) dari sisi admin dan pengguna portability diperoleh hasil sebesar $100 \%$ dengan predikat "sangat tinggi"; 4) aspek kegunaan dari 20 orang responden yang telah menginstal aplikasi tersebut di perangkat android mereka diperoleh hasil sebesar 1607 dengan predikat "sangat layak". Hasil pengujian aplikasi "Trilingual Bahasa Indonesia, Gorontalo dan Suwawa" dapat dikatakan memberikan hasil bahwa aplikasi ini telah memiliki kemapuan secara efisien, serta stabil dan dapat di pasang pada minimal versi android 4.0 Ice Cream Sandwitch, dan mudah digunakan oleh pengguna yang belum mengetahui apliaksi tersebut sehingga disebut juga telah sesuai dengan kaidah sebagia mana yang telah di tetepkan sesuai dengan kulitas perangkat lunak pada ponsel cerdas.

Peneliti mempunyai masukan dan saran dari sis perangkat lunak yang dikembangkan, untuk dilengkapi fitur kontak pengembang agar para pengguna aplkiasi kamus trilingual dapa tmemberikan masukan kepada pengembang untuk dilakukan perbaik-perbaik sehingga aplkasi ini menjadi lebih baik kedepannya.

\section{DAFTAR PUSTAKA}

Agarwal, B. B., Tayal, S. P., dan Gupta, M., 2010. Software Engineering and Testing, Burlington, USA: Jones \& Bartlett Learning.

David, Assaf Ben. 2011. Mobile Aplication Testing Best Practices to Ensure Quality. Amdocs, 2.

Irwansyah, Edy. Moniaga, Jurike V. 2014. Pengantar Teknologi Informasi. Yogyakarta: Deepublish.

ISO/IEC. (2011). Systems and software engineering - Systems and software Quality Requirements and Evaluation (SQuaRE) System and software quality models (ISO/IEC 25010:2011 ). Switzerland: ISO office.

Malingo Mances., 2012. “Aplikasi Bilingual (Gorontalo-Indonesia) Berbasis Sistem Operasi Android" (Tugas akhir).

Pateda Mansoer., 1976. "Kamus bahasa GorontaloIndonesia".

Pomanto Hais., 2013. "Pengembangan Aplikasi Bilingual Indonesia-Gorontalo dan Gorontalo -Indonesia Menggunakan Android dan PHP” (Tugas akhir).

Pressman, Roger S. (2002). Rekayasa Perangkat Lunak: Pendekatan Praktisi (Buku 1). Yogyakarta: Andi.

Budi Raharjo,Imam Heryanto. (2014). MODUL PEMROGRAMAN WEB HTML,PHP \& MYSQL (Revisi Kedua). Bandung: Modula.

Rizky, Soetam., 2011. Konsep Dasar Rekayasa Perangkat Lunak. Jakarta: Prestasi Pustaka.

Safaat H Nazruddin , 2012 "Pemrograman mobile smartphone dan tablet pc berbasis Android".

Sommerville, Ian. (2003). Software Engineering (Rekayasa Perangkat Lunak)/Edisi 6/Jilid 2. Jakarta: Erlangga.

Sugiarti Yuni, 2013 “Analisis \& Perancangan UML (Unified - Modeling Language) Generated VB.6".

Supardi Yuniar, 2014 "Semua bisa menjadi programmer Android". http://www.gorontaloprov.go.id/profil/sejar ah 